\title{
Acento prosódico y acentuación gráfica en español
}

Recibido: 6/11/2014

Aceptado: 27/03/2015

\section{RESUMEN:}

El presente trabajo, enfocado desde la perspectiva historiográfica, consta de tres partes. En la primera, que constituye el marco teórico general, se estudia la naturaleza del prosodema acentual. En la segunda se analizan las peculiaridades del acento prosódico, sus funciones, las unidades a las que afecta y los fenómenos a los que da lugar. Y en la tercera se examinan los criterios en los que se han basado las normas del código uniforme de su representación gráfica.

PALABRAS CLAVE: español, acento, prosodema, acentuación gráfica, código.

\section{ABSTRACT:}

This article, which is focused from the historiographical perspective, comprises three parts. In the first part, which develops the general theoretical framework, the nature of the prosodeme of Spanish accent is studied. The second part analyzes the specific features of Spanish prosodic accent, its functions, the units that are affected and the phenomena that these cause. Finally, the third part examines the criteria used to set the rules for the uniform code of Spanish accent graphic representation.

KEY WORDS: Spanish, accent, prosodeme, graphic accentuation, code.

\section{Introducción}

El acento es un prosodema que, como tal, afecta a unidades lingüísticas de la cadena hablada superiores al sonido - o al mis- 
mo sonido en aquellos casos en que se comporta como estas - al poner de relieve una determinada sílaba con respecto a las de su entorno. El acento prosódico, que existe en la mayor parte de las lenguas aunque no responde a idénticos parámetros ni desempeña la misma función en todas ellas, en algunas no se representa gráficamente y en otras solo se indica en ciertos casos. La ortografía del español, de la manera en que está fijada, lo señala de forma regular y prácticamente exhaustiva.

En la investigación del acento en español tradicionalmente se han distinguido dos tendencias, la de quienes sostienen que está en función del tono - o de la cantidad y el tono- y la de aquellos otros que consideran que es una mera consecuencia de la intensidad. En la primera, la Real Academia Española, basándose únicamente en el tono, lo presenta en la GRAE como "la máxima entonación con que en cada palabra se pronuncia una sílaba determinada" ${ }^{\prime \prime}$, mientras que Andrés Bello, al considerar que está en función de la cantidad y el tono, establece que "consiste en una levísima prolongación de la vocal que se acentúa, acompañada de una ligera elevación del tono" ${ }^{2}$.

Dentro de la segunda, Rufino José Cuervo parte de la idea de que "por el acento se realza una sílaba entre las demás de una palabra, o una sílaba que de por sí forma palabra entre otras sílabas inmediatas" ${ }^{3}$, señalando a continuación que esto se logra "o aumentando la espiración con que producimos el sonido o alzando

1 Real Academia Española, Gramática de la lengua española, Nueva edición reformada, de 1931, y apéndice con las Nuevas normas de prosodia y ortografía declaradas de aplicación preceptiva desde $1^{\circ}$ de enero de 1959, Madrid, Espasa-Calpe, 1962, pág. 459.

2 Bello, Andrés, Gramática de la lengua castellana destinada al uso de los americanos. Con las Notas de Rufino José Cuervo. Estudio y edición de Ramón Trujillo, Madrid, Arco/Libros, 1988, pág. 173.

3 Cuervo, Rufino José, Notas a la Gramática de la lengua castellana de don Andrés Bello. Edición, variantes y estudio preliminar por Ignacio Ahumada Lara, Bogotá, Instituto Caro y Cuervo, 1981, pág. 44. 
el tono: el primer acento, llamado de intensidad o espiratorio, es el que conocemos en castellano y en las más de las lenguas europeas modernas" 4 , para concluir que "al definir nuestro acento debemos caracterizarlo por la mayor intensidad" 5 .

Tomás Navarro Tomás, desde esta perspectiva, titula Intensidad al capítulo dedicado al acento en su Manual de pronunciación española, donde afirma que "el oído español es evidentemente más sensible a las modificaciones del acento de intensidad que a las de otros elementos fonéticos" ${ }^{\prime \prime}$. Más adelante apunta que en la pronunciación de las palabras consideradas aisladamente "coinciden en líneas generales el tono y el acento de intensidad, recayendo de ordinario el tono normal sobre la misma sílaba que lleva el acento y pronunciándose por debajo de este tono, con inflexión ascendente o descendente, según los casos, las demás sílabas de la palabra"7.

Aunando las dos posiciones mencionadas, Salvador Fernández Ramírez sostiene que "acento de intensidad y acento melódico caracterizan, por lo tanto, la estructura fonética de la lengua española, sin un predominio destacado de uno sobre otro, como ocurre en las lenguas antiguas y modernas" ${ }^{\prime 8}$. En el Esbozo se lee que "tono e intensidad desempeñan así una función fonológica que consiste en poner de relieve determinada o determinadas sílabas, en contraste con las demás, que las preceden o las si-

4 Cuervo, Rufino José, Notas..., pág. 44.

5 Cuervo, Rufino José, ibid., pág. 44.

6 Navarro Tomás, Tomás, Manual de pronunciación española, 28. ed. ed., Madrid, CSIC, 2004, pág. 183.

7 En el Manual de entonación española, Tomás Navarro Tomás comenta que "el elemento esencial en la estructura prosódica de las palabras es en español el acento dinámico o de intensidad" (Navarro Tomás, Tomás, Manual de entonación española, 4. ㄹ ed., Madrid, Guadarrama, 1974, pág. 21).

8 Fernández Ramírez, Salvador, Gramática española. 2. Los sonidos. Volumen preparado por José Polo, Madrid, Arco/Libros, 1986, pág. 25. 
guen. Pero el oído es mucho más sensible a la tonalidad que a la intensidad" 9 . Emilio Alarcos Llorach interpreta igualmente que el acento "en español se realiza mediante el incremento de la intensidad espiratoria (y la elevación del tono) en una sola sílaba determinada del significante" ${ }^{\prime 10}$.

En el primer trabajo notable enfocado desde la perspectiva acústica, Dwight L. Bolinger y Marion Hodapp observan que "el tono es el elemento imperante en el acento del español"11, y la intensidad y la duración, factores secundarios, lo que no implica que tenga que producirse forzosamente una elevación del mismo por encima del cuerpo tonal de la frase, sino simplemente "una salida de ella, sea para arriba o para abajo. Los descensos no abundan tanto como las subidas, pero son, sin embargo, frecuentes" ${ }^{\prime 2}$. Heles Contreras, que corrobora y complementa la tesis de estos autores, matiza que el tono es el elemento principal, la "clave del acento"13, y que la intensidad desempeña un papel más secundario que la duración.

Antonio Quilis, que define el acento como un prosodema "que permite poner de relieve una unidad lingüística superior al fonema (sílaba, morfema, palabra, sintagma, frase; o un fonema,

9 Real Academia Española, Esbozo de una nueva gramática de la lengua española, Madrid, Espasa Calpe, 1973, pág. 64.

10 Alarcos Llorach, Emilio, Gramática de la lengua española, Madrid, Real Academia Española, Colección Nebrija y Bello, Espasa, 1994, pág. 45. En el DRAE, el acento (< lat. accentus, calco del gr. $\pi \varrho 0 \sigma \omega \delta i ́ \alpha)$ es definido por la Real Academia Española en la misma línea como el "relieve que en la pronunciación se da a una sílaba de la palabra, distinguiéndola de las demás por una mayor intensidad o por un tono más alto" (Real Academia Española, Diccionario de la lengua española, 23. a ed., Madrid, Espasa Calpe, 2014, s. v. acento).

11 Bolinger, Dwight L. y Hodapp, Marion, "Acento melódico. Acento de intensidad", BFUCh, 13, 1961, pág. 47.

12 Bolinger, Dwight L. y Hodapp, Marion, “Acento melódico...", pág. 35.

13 Contreras, Heles, “Sobre el acento en español”, BFUCh, 15, 1963, pág. 237. 
cuando funciona como unidad superior) para diferenciarla de otras unidades lingüísticas del mismo nivel"14, del mismo modo que Dwight L. Bolinger y Marion Hodapp, y Heles Contreras, en su producción y percepción concede el papel predominante a la frecuencia del fundamental, sola o acompañada de la duración, que, a su juicio, ocupa el segundo lugar en orden de importancia, ya que solo en contadas ocasiones, "cuando no actúan ni la frecuencia del fundamental, ni la duración, es la intensidad la que pone de relieve el prosodema acentual"15.

Al tratar de las variables fonéticas, Joaquim Llisterri Boix indica que el acento tiene una clara incidencia en las características acústicas, articulatorias y perceptivas de los sonidos debido a que "puede causar variaciones en la intensidad, la frecuencia del fundamental, la frecuencia de los formantes y la duración" ${ }^{16}$. Por su parte, Eugenio Martínez Celdrán, si bien es cierto que "hay autores que destacan la elevación del $\mathrm{F}_{0^{\prime}}$ otros la duración, aunque es posible que sea una combinación de ambos la que proporciona la prominencia de la sílaba acentuada frente a sus vecinas

14 Quilis, Antonio, Tratado de fonología y fonética españolas, 2. ․ ed., Madrid, Gredos, 2006, pág. 388 .

15 Quilis, Antonio, Tratado..., pág. 400. Celia Casado Fresnillo, Andrés Santos y Emilia V. Enríquez, basándose en la síntesis del lenguaje, de acuerdo con la sugerencia de Antonio Quilis (Quilis, Antonio, Fonética acústica de la lengua española, Madrid, Gredos, 1981, pág. 332), llegan a la conclusión de que “de las tres variables estudiadas parece que, efectivamente, es la Frecuencia Fundamental la que determina siempre una mayor percepción del acento y, por tanto, refrena más la subjetividad del oyente, mientras que la actuación de la Duración depende mucho más del tipo de esquema acentual de la palabra. Así, se confirman y precisan algo más las observaciones que en su día hicieron Bolinger, Hodapp, Heles Contreras o, más recientemente, Antonio Quilis, y que ya entrevió, de modo intuitivo, Andrés Bello, mientras que, en efecto, la influencia de la Intensidad en el acento español parece, hoy por hoy, poder desecharse" (Casado Fresnillo, Celia; Santos, Andrés y Enríquez, Emilia V., "La percepción del acento en español”, Lingüística Española Actual, 11, 1989, pág. 268).

16 Llisterri Boix, Joaquim, Introducción a la fonética. El método experimental, Barcelona, Anthropos, 1991, pág. 83. 
inacentuadas"17, subraya que "la amplitud no parece que juegue un papel demasiado relevante en esta prominencia"18.

Antonio Pamies Bertrán, basándose en los datos obtenidos en el análisis acústico computerizado de un corpus de 57 modelos de enunciado en siete lenguas (francés, español, catalán, portugués, italiano, inglés, ruso), en el que mide la duración, la intensidad y el tono de las vocales situadas en posición no final y discontigua, llega a la conclusión de que en estas lenguas existen al menos dos mecanismos para la marca del acento en tales posiciones: "1) Puede actuar una ley de compensación permanente entre los tres factores, como parece ocurrir en francés, inglés, ruso y español. // 2) Puede actuar la duración vocálica como marcador por defecto, apoyada por una ley de compensación subsidiaria entre duración e intensidad, como ocurre en italiano, catalán y portugués"19.

17 Martínez Celdrán, Eugenio, Análisis espectrográfico de los sonidos del habla, 2. ed., Barcelona, Ariel, 2007, pág. 107.

18 Martínez Celdrán, Eugenio, Análisis espectrográfico..., pág. 107. En el Manual de fonética española, este mismo autor y Ana M. a Fernández Planas ponen de relieve el hecho de que Tomás Navarro Tomás admitiera que el tono sea un parámetro importante en la detección del acento, y explican que otros autores posteriores "confirman y añaden que la duración es el segundo parámetro en orden de relevancia. Descartamos, pues, la intensidad como parámetro determinante" (Martínez Celdrán, Eugenio y Fernández Planas, Ana M. a, Manual de fonética española. Articulaciones y sonidos del español, 2. a ed., Barcelona, Ariel, 2013, págs. 199-200).

19 Pamies Bertrán, Antonio, “Consideraciones sobre la marca acústica del acento fonológico", Estudios de Fonética Experimental, VIII, 1996, pág. 40. Este lingüista, en otro trabajo previo - titulado "Los acentos contiguos en español”, extraído de su tesis doctoral Acento, ritmo y lenguaje, dirigida por el Dr. Juan de Dios Luque Durán, leída y aprobada en la Universidad de Granada en 1994-, en el que había examinado desde el punto de vista acústico y fonológico la posibilidad de que, como ya se enseñaba desde hace más de un siglo en algunos tratados de métrica, un acento resulte anulado por el acento vecino en caso de contigüidad en español - en la tesis estudia también el problema en francés, inglés, portugués, italiano, catalán y ruso, donde la polémica también aparece en la literatura sobre el tema-, había comprobado que "existe un indudable debilitamiento acústico de uno de ellos, interpretable fonológicamente como una neutralización de la oposición [ \pm acento] causada por 
A la luz de los resultados de las investigaciones y trabajos experimentales, la Real Academia Española y la Asociación de Academias de la Lengua Española presentan el acento del español como un fenómeno complejo en el que intervienen diferentes parámetros acústicos de los cuales el factor más relevante en su producción y percepción es el tono, sobre todo en la acentuación de las palabras pronunciadas aisladamente, asociado por lo común a un aumento de la duración o la intensidad:

Desde el punto de vista fonético, el acento prosódico se manifiesta acústicamente gracias a la combinación de las variaciones de los valores de tres parámetros en la articulación de la vocal: el TONO, la DURACión y la INTENSIDAD. Actualmente se considera que el correlato acústico principal de la impresión auditiva del tono es la FRECUENCIA FUNDAMENTAL $\left(\mathrm{F}_{\mathrm{o}}\right)$, que articulatoriamente se corresponde con la frecuencia vibratoria de las cuerdas vocales y se mide en ciclos por segundo o hercios $(\mathrm{Hz})^{20}$.

\section{Acento prosódico}

El acento se distingue fonológicamente de los segmentos ante todo por el hecho de que, mientras que en el análisis de estos se tiene en cuenta solo un conjunto limitado de elementos (modo de articulación, lugar de articulación, acción de las cuerdas vocales,

el contexto, semejante a la neutralización de los tonos en chino" (Pamies Bertrán, Antonio, "Los acentos contiguos en español”, Estudios de Fonética Experimental, VI, 1994, pág. 93).

20 Real Academia Española y Asociación de Academias de la Lengua Española, Nueva gramática de la lengua española. Fonética y fonología, Madrid, Espasa Libros, 2011, pág. 465. La Real Academia Española y la Asociación de Academias de la Lengua Española añaden que la duración, que "depende del tiempo durante el cual se prolonga el movimiento vibratorio de las cuerdas vocales" (Real Academia Española y Asociación de Academias de la Lengua Española, Nueva gramática de la lengua española. Fonética y fonología..., pág. 365), se mide en milésimas de segundo (ms), y la intensidad, que "implica un aumento del esfuerzo muscular durante la pronunciación de un sonido determinado" (Real Academia Española y Asociación de Academias de la Lengua Española, Nueva gramática de la lengua española. Fonética y fonología..., pág. 365), en decibelios (dB). 
acción del velo del paladar...) que se combinan en el acto de habla sin necesidad de recurrir a otros rasgos del enunciado oral, en el suyo se requiere la comparación de dos o más puntos de la cadena sonora, ya que, si se identifica una sílaba acentuada o tónica en un enunciado es porque existe en él otra inacentuada o átona, como en iQuédate ahí!, donde las sílabas Qué e hí se contraponen a las demás por su acento, siendo susceptibles las vocales é e $i$ de ser definidas como tales sin que sea preciso recurrir a otros segmentos contrastivos.

A diferencia de lo que sucede en las lenguas de acento fijo (como el francés o el turco, en las que este incide siempre sobre la última sílaba de la palabra; el finés o el checo, en las que se sitúa en la primera; o el polaco, que lo lleva en la penúltima) o las de acento condicionado (como el latín, en la que está condicionado por la cantidad de la penúltima sílaba, de manera que si esta es larga recae sobre ella y si es breve lo hace sobre la antepenúltima), en español, lengua de acento libre igual que el inglés o el italiano, puede ocupar diferentes posiciones sin predeterminación alguna (la última, la penúltima, la antepenúltima o, solo excepcionalmente, una de las anteriores a la antepenúltima).

El acento, de acuerdo con la estructura interna de las lenguas, desempeña en principio las funciones contrastiva (en el eje sintagmático, en las de acento fijo o libre, al poner de relieve las sílabas acentuadas frente a las no acentuadas), distintiva (en el eje paradigmático, en las de acento libre, al distinguir dos unidades de significado diferente), demarcativa (en las de acento fijo, al señalar los límites de las unidades en la secuencia: el final de una palabra, como en francés o en turco; el principio, como en checo; o un punto intermedio entre el principio y el final, como en polaco) y culminativa (en las de acento libre o combinado, al señalar la presencia de una unidad acentual en una palabra pero sin indicar los límites) ${ }^{21}$.

21 Quilis, Antonio, Tratado..., págs. 388-389; Hidalgo Navarro, Antonio y Quilis Merín, Mercedes, Fonética y fonología españolas, 2. a ed., Valencia, Tirant lo Blanch, 2004, págs. 228-229. 
De estas funciones, el acento cumple en español la contrastiva, la distintiva y la culminativa. Por medio de la primera establece un contraste o diferenciación entre las sílabas acentuadas y las inacentuadas de la cadena hablada: cán-ta-ro; por la segunda distingue dos o más signos lingüísticos: llame / llamé; límite / limite / limité; y mediante la tercera permite detectar los diferentes grupos acentuales del discurso, constituidos por una sílaba tónica y las átonas de su entorno que se apoyan en ella (Cuando venga, I avísame), sin formar parte de la misma palabra (Cuando venga) o formando parte de ella: avísame ${ }^{22}$.

El acento, en cuanto suprasegmento, se encuentra asociado a una sílaba, caracterizándose como el mayor grado de prominencia con el que se pronuncia esta en relación con las otras de la misma palabra o el grupo acentual del que forma parte, de donde surge el contraste entre sílabas fuertes o tónicas y sílabas débiles o átonas, como en la palabra mesa, en la que la sílaba me adquiere un relieve especial en comparación con la sílaba $s a$, o en la secuencia Se lo encomendó, en la que se localiza en la última sílaba, dó, mientras que las restantes son inacentuadas.

Como se ve, la unidad lingüística básica a la que afecta el prosodema acentual es la sílaba, que suele constar de más de un fonema, aunque en ocasiones está constituida por uno solo. En la estructura interna de la sílaba se distinguen tres componentes, uno imprescindible, el núcleo vocálico, que presenta una mayor abertura, frecuencia, intensidad, duración, sonoridad y perceptibilidad, y dos márgenes consonánticos, uno prenuclear y otro posnuclear, con estas características en un grado sensiblemente disminuido. El núcleo debe hallarse integrado al menos por una vocal ( $a r-t e)$, o bien por dos, en los diptongos (a-gua), o por un máximo de tres, en los triptongos: a-ve-ri-güéis. Los márgenes, cuando existen, pueden estar formados por una o dos consonantes: trans-fe-rir. 
Los diptongos, secuencias de dos vocales que se pronuncian en la misma sílaba, normativamente pueden estar constituidos por vocal cerrada /i, u/ + vocal abierta /a, e, o/ (diptongos crecientes, en los que primer elemento actúa fonéticamente como semiconsonante $[\mathrm{j}, \mathrm{w}]$ y el segundo como núcleo silábico) (o-diar, pier-de, ra-dio) o vocal abierta /a, e, o/ + vocal cerrada /i, u/ (diptongos decrecientes, cuyo primer elemento es el núcleo silábico y el segundo la semivocal [i, u] $)(a i-r e, l e y$, soy), y con menor frecuencia vocal cerrada /i, u/ + vocal cerrada /u, i/, en cuyo caso la vocal nuclear es la que mayor intensidad posea por pequeña que sea la diferencia, normalmente la segunda: ciu-dad, muy ${ }^{23}$. Los triptongos, secuencias de tres vocales pronunciadas en la misma sílaba, están formados por vocal cerrada /i, u/ (fonéticamente, semiconsonante $[\mathrm{j}, \mathrm{w}]$ ) + vocal abierta /a, e, o/ (núcleo silábico) + vocal cerrada /i, u/ (fonéticamente, semivocal [i, un]): despreciáis, atestigüéis.

Los hiatos, secuencias de dos vocales pronunciadas en sílabas distintas en una palabra, responden a las combinaciones de vocal cerrada tónica /i, u/ + vocal abierta átona /a, e, o/ (ha-cí-a, ríe, con-ti-nú-o), vocal abierta átona /a, e, o/ + vocal cerrada tónica /i, u/ (la-úd, se-ís-mo, o-í-do), vocal abierta /a, e, o/ + vocal abierta /a, e, o/ (ca-er, re-o, lo-a) o dos vocales iguales: al-ba-ha-ca, lo-or, du-un-vi-ra-to. También se pueden pronunciar con hiato algunas de las secuencias vocálicas anotadas para los diptongos, como la de vocal cerrada átona /i, u/ + vocal abierta (con-fi-é, ac-tu-ó) o la de dos vocales cerradas distintas (in-clu-i-do, di-ur-no), y para los triptongos, como la formada por dos de las tres vocales contiguas: ac-tu-áis, con-fi-éis.

En la actualidad, la Real Academia Española y la Asociación de Academias de la Lengua Española se muestran sensibles al hecho de que la realización de las secuencias vocálicas interpre-

23 No obstante, en algunas palabras, como cocuy o huy, el núcleo silábico suele ser la primera vocal, realizándose esta como tónica y la segunda como semivocal [úi]. 
tadas tradicionalmente como hiatos en el español normativo "no es general entre los hispanohablantes, ya que buena parte de ellos pronuncian en estos mismos casos diptongos o triptongos" ${ }^{24}$, registrándose articulaciones como con-fié, ac-tuó, in-clui-do, diur-no, como diptongos, o ac-tuáis, con-fiéis, como triptongos, especialmente entre hablantes procedentes "de México, Centroamérica y parte de las áreas caribeña y andina" ${ }^{25}$.

Por otro lado, debido a la tendencia antihiática de la lengua española, en el habla relajada de España y América con frecuencia se pronuncian en una misma sílaba secuencias formadas por dos vocales abiertas distintas, sobre todo si ambas son átonas - fenómeno conocido con el nombre de sinéresis- (tea-tro, gol-pear, co-reó-gra-fo $)^{26}$, produciéndose a menudo el cierre de la primera vocal en el habla popular de algunas zonas e incluso en el nivel culto de algunos países de América (tia-tro, gol-piar, co-rió-gra-fo), a pesar de lo cual la Real Academia Española y la Asociación de Academias consideran que, "con independencia de su pronunciación real en cada palabra por parte de hablantes concretos, las secuencias de dos vocales abiertas se consideran siempre hiatos desde el punto de vista normativo" ${ }^{27}$.

En nuestro sistema lingüístico, por el acento, se distinguen palabras acentuadas o tónicas y palabras inacentuadas o átonas. Las primeras poseen un acento denominado acento léxico o acento primario. Las segundas se agrupan con aquellas para

24 Real Academia Española y Asociación de Academias de la Lengua Española, Ortografía de la lengua española, Madrid, Espasa Libros, 2010, pág. 199.

25 Real Academia Española y Asociación de Academias de la Lengua Española, Ortografía..., 2010, pág. 198.

26 Caso similar es el que se registra a menudo en la cadena hablada con la sinalefa, como en "la envidia" (laen-vi-dia), "me alegro" (mea-le-gro), "poco efecto": po-coe-fec-to.

27 Real Academia Española y Asociación de Academias de la Lengua Española, Ortografía..., 2010, pág. 199. 
formar un grupo acentual, como el director o del periódico. Varias unidades de este tipo configuran otra mayor, el grupo fónico $(e l$ director del periódico), la cual, a su vez, puede contribuir a la construcción de unidades más complejas, llamadas unidades melódicas (El director del periódico / se negó a publicar el anuncio), cuya prominencia es marcada por el acento sintáctico o acento máximo. Tanto en el dominio de la palabra como en los superiores, las prominencias menores se representan mediante el acento secundario: coméntaselò.

En la fonología actual, el pie métrico, concepto de la métrica clásica que sirve de base para la asignación del acento, es un constituyente prosódico que incluye dos elementos, uno más prominente (fuerte) que el otro (débil), que pueden seguir dos combinaciones, elemento fuerte + elemento débil, conocida como troqueo o pie trocaico, con la prominencia en primer lugar o a la izquierda, o elemento débil + elemento fuerte, con la que se forma un yambo o pie yámbico, cuya prominencia se sitúa en segundo lugar o a la derecha ${ }^{28}$.

La mayor parte de los análisis efectuados hasta el momento coinciden en que los pies métricos característicos del español son los troqueos. Sin embargo, no existe acuerdo en si la estructura acentual es sensible a la cantidad como en latín o si se comporta de manera ajena a este rasgo. Algunos autores, basándose en las reglas de asignación del acento, sostienen que este presenta una naturaleza mixta, según la cual determinados factores fonológicos y morfológicos determinan que su posición sea predecible o impredecible.

La restricción de asignación de acento más notable es la que establece que este solo puede recaer sobre alguna de las tres últimas sílabas, propiedad de muchas lenguas - que poseía también el latín - denominada en los estudios fonológicos ventana de tres sílabas. Esta restricción explica, por ejemplo, que el plural

28 Real Academia Española y Asociación de Academias de la Lengua Española, Nueva gramática de la lengua española. Fonética y fonología..., pág. 359. 
de espécimen sea especímenes y no *espécimenes. El acento, por tanto, con independencia del número de sílabas de que conste la palabra, únicamente puede ocupar la última, la penúltima o la antepenúltima sílaba de la palabra, con la única excepción de las estructuras constituidas por verbo + clíticos: cuéntamelo.

Las palabras del español, por la posición del acento, de acuerdo con restricción de la ventana de tres sílabas, pueden ser agudas u oxítonas, si se sitúa en la última sílaba: café; llanas, graves o paroxítonas, cuando recae sobre la penúltima: árbol; y esdrújulas o proparoxítonas, en aquellos otros casos en los que la sílaba acentuada es la antepenúltima: pájaro. En las voces sobresdrújulas o superproparoxítonas, en las que el acento se ubica en una de las sílabas anteriores a la antepenúltima (cómetelo, imagínatemela), el dominio de este es la forma verbal, en cuya localización no influyen los clíticos.

En los trabajos llevados a cabo por Antonio Quilis sobre la frecuencia de los esquemas acentuales en español ${ }^{29}$ se observa que son más abundantes las palabras acentuadas o tónicas $(63,44$ $\%$ ) que las inacentuadas o átonas (36,56\%). De las acentuadas o tónicas, las más numerosas son las bisílabas $(41,98 \%)$, seguidas de las monosílabas $(27,72 \%)$, alcanzando la mayor frecuencia de aparición las llanas (33,83\%). Las inacentuadas o átonas son en su inmensa mayoría monosílabas $(90,23 \%)$, frente a la palpable minoría de las bisílabas (9,77 \%).

En español, por regla general, las palabras acentuadas o tónicas son el sustantivo: "el libro"; el adjetivo: "una chaqueta azul"; el verbo: canta; el adverbio: "Se levanta temprano"30; los pronombres personales tónicos: "Condujo el coche él"; los pro-

29 Quilis, Antonio, “Frecuencia de los esquemas acentuales en español”, en Estudios ofrecidos a Emilio Alarcos Llorach, V, Universidad de Oviedo, 1983, págs. 113126, y Tratado..., págs. 400-403.

30 Los adverbios en -mente son portadores de dos sílabas tónicas: “Recitó el poema maraviLLOsaMENte". 
nombres posesivos: "Ese ordenador es suyo"; los determinantes y pronombres demostrativos: "esta [página]"; los determinantes y pronombres numerales, cardinales ("siete [días]") y ordinales: "séptimo [lugar]"; los determinantes, pronombres y adverbios indefinidos: "bastantes [naranjas]", "Come bastante"; y los determinantes, pronombres y adverbios interrogativos ("¿Qué curso estudias?”, “QQuién es?”, “ ¿Cómo lo has hecho?”) y exclamativos: "iqué casualidad!", “iQuién lo diría!”, “ ¡Cómo resiste!”31.

Las palabras inacentuadas o átonas en español, con las excepciones aisladas que acabamos de anotar, son el artículo ("la ciudad"), la preposición ("Residió en Toledo"), la conjunción ("Fortunata y Jacinta"), los pronombres personales átonos ("Se lo dijo"), los determinantes posesivos ("su tutor"), ciertos sustantivos empleados como fórmulas de tratamiento antepuestos a nombres propios ("don Clemente") y los relativos: "Ese es el grupo que le corresponde". Además, algunas palabras acentuadas o tónicas se pronuncian como inacentuadas o átonas cuando forman parte como primer elemento de expresiones pluriverbales constituidas por la yuxtaposición de dos unidades simples, en antropónimos (Luis Alberto") y topónimos ("Nueva York"), numerales ("tres mil") o vocativos: "Buen hombre, respire hondo".

En el grupo fónico y en la unidad melódica, las palabras acentuadas o tónicas muestran diferentes grados de prominencia. El acento sintáctico o acento máximo, que suele aparecer al final de las unidades demarcativas, permite al interlocutor establecer perceptivamente los límites entre las unidades prosódicas al otorgar mayor prominencia al acento primario final, el situado más a la derecha en la frase. Así, en el enunciado Ana comió, el acento sintáctico o acento máximo está localizado en la sílaba mió; en Ana comió a las dos, dicha prominencia acentual recae so-

31 A esta relación hemos añadir el relativo cual, cuando va precedido de artículo ("Ese es el motivo por el cual usa gafas") y en ciertas expresiones fijas: "Son tal para cual"; la conjunción y en enunciados interrogativos encabezando el esquema sintagmático: “¿Y Juan...?”, “¿Y si nos descubren...?”; y la preposición según: “La sociedad según Aristóteles". 
bre dos; y en Ana comió a las dos del mediodía, el acento en cuestión se encuentra en dí. El desplazamiento acentual en estos ejemplos, desde el punto de vista acústico, se manifiesta a través de un aumento destacado de la duración de la sílaba acentuada - mió, dos, dí-, dado que el perfil entonativo presenta un final descendente y el acento no puede manifestarse a través de un aumento del tono.

Cuando en el dominio del enunciado aparecen dos acentos léxicos contiguos o muy próximos, se produce lo que se ha dado en llamar un choque acentual, fenómeno que los hablantes tienden a evitar con frecuencia haciendo coincidir la prominencia máxima con el primer acento, como en beBER VIno, donde el tono más agudo se corresponde con la realización de la sílaba ber, sobre la que recae el acento sintáctico o acento máximo, o desplazando hacia la izquierda el primer acento, como en José Juan o María Luisa, en los casos en los que se pronuncian con los dos acentos léxicos. Si el choque acentual se produce entre dos sílabas acentuadas cercanas, como en toMARse un reFRESco, el grado de prominencia de estas puede igualarse, presentando entonces el enunciado dos acentos sintácticos o máximos ${ }^{32}$.

Para dar un especial relieve a una determinada palabra o a una parte del enunciado, los hablantes se sirven en ocasiones del acento enfático o de insistencia. De esta manera, en Él lo ha dicho, el acento enfático, que recae sobre el pronombre personal sujeto $E ́ l$, desde el punto de vista fonético se manifiesta mediante una destacada elevación del tono fundamental que contrasta con los otros elementos de la secuencia y desde la perspectiva semántica ejerce una función focalizadora ${ }^{33}$ por la cual no deja lugar a du-

32 Dorta Luis, Josefa y Hernández Díaz, Beatriz, “El choque de acentos en español", Síntesis Tecnológica, vol. 3, n.․2, 2007, págs. 111-123.

33 Zubizarreta, María Luisa, “Las funciones informativas: tema y foco”, en Bosque, Ignacio y Demonte, Violeta (dirs.), Gramática descriptiva de la lengua española. Preámbulo de Fernando Lázaro Carreter, 3. Entre la oración y el discurso. Mofología, Madrid, Real Academia Española, Colección Nebrija y Bello, 1999, pág. 4228; Ocam- 
das acerca de quién ha realizado la acción ('ha sido él y no otro'). Otras veces, por medio de este tipo de acento se destaca una de las sílabas inacentuadas o átonas de la palabra ("bajo mi responsabilidad") o incluso una palabra de esta índole: "Lo hospedaré en mí casa".

En el dominio superior a la palabra, el acento y la entonación se hallan estrechamente ligados debido a que las sílabas acentuadas o tónicas suelen actuar como los puntos de anclaje de las inflexiones melódicas, de los acentos tonales, que se definen como movimientos ascendentes o descendentes del tono fundamental. En este sentido, si comparamos las secuencias que lo mandaba y que no mandaba, observamos que en la primera de ellas el acento tonal ascendente está asociado al acento sintáctico o acento máximo, que recae sobre la sílaba $d a$, mientras que en la segunda, en la que el adverbio de negación está focalizado, la inflexión tonal ascendente coincide con la realización de la sílaba no.

En las estructuras rítmicas de los enunciados, que adquieren mayor importancia en el lenguaje poético, basado en la repetición de alternancias de elementos marcados y no marcados, similar a la de una composición musical, el funcionamiento del acento constituye la base. Como apunta Antonio Quilis, en la sílaba que configura la rima en la métrica, “además de darse la culminación temporal, la reiteración de timbre y la inflexión melódica, recae también el acento, conjugándose plenamente las tres funciones indicadas, e incluso potenciándose la culminativa" ${ }^{34}$.

El grupo fónico más habitual en este registro es el de ocho sílabas, que, por lo común, configura por sí mismo una unidad melódica y el patrón de verso más frecuente en español. El acen-

po, Francisco, "On the Notion of Focus in Spoken Spanish: An Empirical Approach", in Kempchinsky, Paula and Piñeros, Carlos Eduardo (eds.), Theory, Practice, and Acquisition, Sommerville, Cascadilla Press, 2003, págs. 207-226; Burdach Rudloff, Ana María y Poblete Vallejos, Mario, "El fenómeno de la focalización en el habla pública de Chile”, Onomázein, vol. 1, n.‥ 11, 2005, pág. 27.

34 Quilis, Antonio, Tratado..., pág. 390. 
to sintáctico o acento máximo organiza el verso en diferentes pies, cuyo número y localización originan los diferentes ritmos. La ventana de las tres sílabas y el acento de frase se aplican a todo grupo fónico y especialmente al final del verso, haciendo que este termine en sílaba acentuada o tónica, o en sílaba acentuada o tónica seguida de una o dos sílabas inacentuadas o átonas. Con ello, en la poesía española de metro regular, con rima consonante, con rima asonante o sin rima, la terminación del verso y del hemistiquio en sílaba aguda, llana o esdrújula se somete a la organización prosódica en la recitación.

El acento también es un elemento determinante en la rima del verso, con la diferencia de que mientras que en la aconsonantada se repiten los mismos segmentos, vocálicos y consonánticos, desde la última vocal acentuada o tónica ("Venus se siente generala $\mathrm{y}$, ciegos, / treinta rayos del mar, combos delfines, / la escuadra en la fila arrastran de los griegos" [R. Alberti]), en la asonantada se repiten solo las vocales: "Amarrado al duro banco / de una galera turquesa, / ambas manos en el remo / y ambos ojos en la tierra, / un forzado de Dragut / en la playa de Marbella / se quejaba al ronco son / del remo y de la cadena" (Góngora) ${ }^{35}$.

\section{Acentuación gráfica}

El español es una lengua en cuya configuración ortográfica se ha procurado a lo largo del tiempo que la escritura refleje lo más fielmente posible la pronunciación de los hablantes. Los primeros textos escritos en español -impresos en letra humanistaen los que se emplean signos diacríticos para indicar la sílaba tónica en determinadas palabras datan de mediados del siglo XVI, pero su uso no se convierte en un recurso gráfico habitual hasta

35 En la rima asonantada hay tener en cuenta que, cuando la última palabra del verso es esdrújula, se excluye de la rima la penúltima sílaba (rosa / ór[bi]ta), que las vocales satélites o marginales no cuentan (lira / insid[i]a), y que las terminaciones llanas y esdrújulas cuya última sílaba contiene solamente $i$ o $u$ entran en serie asonantada con las terminaciones e y o, respectivamente: hipó(te)sis / roble; ím(pe)tu / libro. 
el siglo siguiente, por lo que en las primeras ediciones de obras, como el Guzmán de Alfarache (1599), de Mateo Alemán, o las Epístolas familiares (1595), de fray Antonio de Guevara, no se utiliza ningún recurso gráfico para señalar el acento. En el siglo XVII se generaliza el uso de diacríticos acentuales, siendo ya muy pocas las obras que carezcan por completo de ellos, y a partir del XVIII se convierte en una práctica generalizada en todo tipo de obra impresa.

En la segunda mitad del siglo XVI y principios del XVII se emplea sobre todo el acento grave, como en griego e italiano, normalmente sobre la última sílaba de algunas palabras, como las formas verbales agudas de tercera persona del singular del pretérito indefinido (mudò, dexè, igualarà) que sin tilde podían confundirse con otras llanas (mudo, dexe, igualara), o bien en monosílabos constituidos por una sola vocal, como las conjunciones $\grave{e}, \grave{o}, \grave{u}$, la preposición à o la forma verbal à del verbo haber. $\mathrm{El}$ acento circunflejo, además de alternar con el grave en usos similares (mandô, $\hat{a})$, se usaba en voces del tipo de fê o zêr para indicar la presencia originaria de una doble vocal (fee, veer), o en vocablos como traîa o baxîos a imitación de los griegos que tenían las mismas terminaciones, y el agudo, utilizado por regla general en posición interior de palabra, era poco frecuente.

Los autores de tratados ortográficos de este período propusieron algunas reglas al respecto, restringiendo su empleo a determinados casos, especialmente el de las voces con más de una acentuación prosódica posible, el de aquellas cuya acentuación podía resultar dudosa por ser poco comunes, o el de los monosílabos, tanto los constituidos por una sola vocal como los que necesitaban distinguirse de otros pertenecientes a distinta parte de la oración, a diferencia del griego, donde casi todas las palabras llevaban su correspondiente acento gráfico.

Juan López de Velasco, partiendo de la base de que el acento ha de consignarse únicamente cuando sea necesario, dado que 
con él "se quitan de la escriptura muchas dudas" ${ }^{36}$, para determinar las palabras que deben acentuarse propone como regla "trocarles el accento a las sylabas: y quando puesto en las otras donde no le tienen significaren algo, señalarsele en la que le huuiere menester, que a poco tiempo que se haga, se adquirira noticia bastante, y habito para hazerlo despues sin pesadumbre ninguna" ${ }^{37}$.

Con una perspectiva más amplia, Gonzalo Correas establece que "pondrase el azento en el molde en todas las palavras de dos i mas silabas, i en las monosilabas ditongos o tritongos sobre la vokal maior, en ke karga la boz, para diferenziar las palavras semexantes en letras, i diferentes en azento i sinificado" 38 , a lo que añade que en las voces monosílabas, aunque "no es menester poner azento, porke no se puede errar: solamente se pondrá, en las ke ái necesidad de diferenziarlas de otras semexantes" ${ }^{\prime \prime}$, como él (pronombre), sé (verbo saber), dé (verbo dar),é (verbo aver [primera persona]) y á (verbo aver [tercera persona]), frente a $\mathrm{el}$ (artículo), se (pronombre), de (preposición), e (conjunción) y a (preposición), respectivamente ${ }^{40}$.

En gran parte de los tratados ortográficos se daba cuenta de los tres tipos de acento, agudo, grave y circunflejo, y se describían

36 López de Velasco, Juan, Orthographia y pronunciación castellana, Burgos, En casa de Philippe de Iunta, 1582, pág. 294.

37 López de Velasco, Juan, Orthographia y pronunciación..., pág. 299. En la misma línea, Mateo Alemán comenta en tono afable que, "si nos anduviesemos à poner capirotes donde no es necesario, ni pidiendolo las diciones, todo se nos iria en capirotadas; asi, no se deven usar, salvo en la necesidad, ofreciendose duda en el sinificado" (Alemán, Mateo, Ortografia castellana, Mexico, En la imprenta de Ieronimo Balli, 1609, fols. 47r.-47v).

38 Correas, Gonzalo, Ortografia kastellana nueva i perfeta, Salamanka, En kasa de Xazinto Tabernier, 1630, págs. 87-88.

39 Correas, Gonzalo, Ortografia kastellana..., pág. 88.

40 Correas, Gonzalo, ibid., págs. 88-89. 
sus usos, que en repetidas ocasiones se asociaban a la posición de la sílaba tónica, prescribiéndose que el grave debía situarse sobre la última sílaba y el agudo en interior de palabra. Sin embargo, en casi todos ellos sus autores acababan inclinándose por el uso exclusivo de uno de estos signos, por lo común el agudo, en contra de la práctica más común en los textos de entonces, en los cuales el que con mayor asiduidad se empleaba era el grave ${ }^{41}$.

A partir del siglo XVIII, el acento agudo se generaliza en los textos. El circunflejo, situado sobre la vocal siguiente a la ch o la $x$, asume el papel de marca diacrítica de carácter grafemático para resaltar que estas consonantes, en cultismos del tipo de monarchîa o exâmen, representaban, respectivamente, a los fonemas $/ \mathrm{k} /$ $\mathrm{y} / \mathrm{k}+\mathrm{s} /{ }^{42}$. La Real Academia Española, en el "Discurso Proemial de la Orthographía de la Lengua Castellana" (1726), considera el agudo como la forma propia del acento gráfico español, restrin-

41 Así, Gonzalo Correas explica que el acento es "una vírgula levantada enzima inklinada un poko adelante, el ke komunmente llaman agudo desta manera á. Los otros dos grave i zirkunflexo ke inventaron los Griegos, e imitaron en Latin, no son menester en rromanze" (Correas, Gonzalo, ibid., pág. 87).

42 La Real Academia Española emplea el acento circunflejo con esta finalidad en la primera edición de la Orthographía (1741): "Quando la Ch se hubiere de pronunciar como K (dexando su peculiar sonido) se pondrá sobre la vocal siguiente la nota, que los Latinos llaman circunflejo, y nuestros Impresores capucha en esta forma châridad, chôro. // La misma nota, ó capucha se pondrá sobre la vocal, á que hiriesse suave, ó sin pronuncion gutural la x, como en exâmen, exîmio, exêquias, exôrcismo" (Real Academia Española, Orthographía española, Madrid, En la Imprenta de la Real Academia Española, 1741, págs. 258-259). En la cuarta edición del Diccionario (1803), en opinión de José Martínez de Sousa (fijándose solo en la tilde de la vocal que sigue a la ch /k/), "al adoptar otros signos para representar los mismos sonidos, la Academia prescindió de este acento, que no ha vuelto a usarse en voces españolas" (Martínez de Sousa, José, Diccionario de ortografía de la lengua española, Madrid, Paraninfo, 1995, s. v. acento circunflejo); sin embargo, hemos podido comprobar cómo en esta edición sigue utilizándose todavía en la vocal que sigue a la $x / \mathrm{k}+\mathrm{s} /$ (exâltar, exôdo, exôrcizar), mientras que en la edición siguiente (1817) ya no se registra. En este sentido, en la octava edición de la Ortografía (1815), la corporación había manifestado que "cada diccion solo tiene un acento que se pone en la sílaba donde carga mas la pronunciacion, y este se llama acento agudo" (Real Academia Española, Ortografía de la lengua castellana, 8. ed., Madrid, En la Imprenta Real, 1815, pág. 77). 
giendo el uso del grave a las voces monosílabas constituidas por una sola vocal, como la preposición à y las conjunciones è, ò, h̀:

el grave, que es el que baxa obliquamente de la izquierda à la derecha en esta forma, unicamente puede tener uso sobre las quatro vocáles à è ò̀ quando cada una es como voz separada de otras, y hace cabál sentído por sí sola, dexando de ser mera vocál: porque la $Y$, que generalmente está subrogada y admitida para que sirva de conjunción en lugar de la $I$, no le necessita: y assi es error decir que el accento grave sirve para alargar la última sylaba en las voces de dos, tres, quatro, y mas vocáles: como Arnés, Amó, Amará, Enseñará, Apercebirá, porque esto es próprio del accento agúdo, que es el que baxa de la derecha à la izquierda de este modo ', y la razón es porque hace agúda y fuerte la pronunciación: lo que no conviene al grave, que la deprime y modéra... ${ }^{43}$.

Desde entonces, en los sucesivos tratados ortográficos de la Real Academia Española se han ido formulando y revisando las reglas de acentuación gráfica de las palabras "teniendo en cuenta el principio de economía, es decir, sin necesidad de señalarla de manera explícita en todos los casos, sino solo en aquellos en que se considere preciso" ${ }^{\prime 4}$, de manera que las palabras ajustadas al patrón prosódico acentual más común no llevan tilde, mientras que aquellas otras que se encuentran situadas al margen de dicha pauta se marcan gráficamente. Por eso, ya en el "Discurso Proemial..." se prescribe la tilde en las palabras esdrújulas (águila, philósopho, doctíssimo), y en la primera edición de la Orthographía (1741) se determina que los monosílabos no la lleven (dan,

43 Real Academia Española, “Discurso Proemial de la Orthographía de la Lengua Castellana", Diccionario de la lengua castellana, I, Madrid, En la imprenta de Francisco del Hierro, Impresor de la Real Académia Españóla, 1726, pág. LXIV. El acento grave es sustituido definitivamente por el agudo en la tercera edición de la Ortografía (1763).

44 Real Academia Española y Asociación de Academias de la Lengua Española, Ortografía..., 2010, pág. 217. 
de, el, que), norma de la que más adelante se irán exceptuando los afectados por la llamada tilde diacrítica.

En la edición de 1870 de la Gramática, la institución comienza a configurar el sistema acentual que se impondría con el tiempo, mostrándose partidaria de tildar solo las voces polisílabas agudas y esdrújulas con el fin de establecer un sistema de acentuación claro y sencillo; pero, dado que ello obligaría a marcar todos los infinitivos y numerosas voces agudas terminadas en consonante, haciéndose eco de las opiniones ajenas tendentes a la simplificación, opta por acentuar las agudas que acaban en vocal o en $n$ o $s$ (café, serán, quinqués) pero no en cualquier otra consonante. En la edición de 1880 se tildan también las palabras llanas terminadas en consonante distinta de $n$ y s (cárcel, dátil, Túnez) o en dos vocales cuando la primera es cerrada y sobre ella carga la pronunciación: poesía, desvarío, falúa; las agudas con encuentro de vocal abierta con vocal cerrada acentuada: país, raíz, baúl; y las agudas, llanas y esdrújulas que contienen un diptongo que deba acentuarse, en la vocal más abierta o en la segunda si las dos son cerradas: acaricié, después, benjuí. En la edición de 1911 se suprime la tilde de las vocales $a, e, o, u$, con la excepción de "la conjunción $o$ cuando, por hallarse inmediata a cifras, pudiera confundirse con el cero" ${ }^{\prime 4}$.

La reforma del sistema acentual de la Real Academia Española de 1952 y 1959, llevada a cabo por Julio Casares, quien el 8 de noviembre de 1951 había presentado a la junta de la corporación el informe "Problemas de prosodia y ortografía en el Diccionario y en la Gramática", donde manifiesta que aspira solamente "a examinar los casos más frecuentes de acentuación vacilante o contradictoria y a proponer posibles soluciones" ${ }^{\prime 4}$, a pesar del eco que tuvo en el mundo hispánico, apenas afectó a la esencia

45 Real Academia Española, Gramática de la lengua castellana, Madrid, Perlado, Páez y Compañía, 1911, pág. 365.

46 Casares, Julio, "Problemas de prosodia y ortografía en el Diccionario y en la Gramática”, Boletín de la Real Academia Española, XXXI, 1951, pág. 371. 
del sistema por el que se venía rigiendo la acentuación desde hacía casi un siglo al quedar reducida a leves retoques parciales, entre las que se encuentran la eliminación de determinadas tildes o la introducción de otras, dejando a la apreciación personal poner o no algunas, como en este, ese, aquel, con sus femeninos y plurales cuando tienen carácter de pronombre, a no ser que su ausencia pueda producir anfibología.

En el último apartado de las Nuevas normas se indicaba que estas entrarían en vigor en la fecha que acordara la Academia (el 1 de septiembre de 1952), pero su aplicación sería potestativa hasta que las innovaciones fueran incluidas en una nueva edición reformada de la Gramática. Tras la celebración del Segundo Congreso de Academias de la Lengua Española (celebrado en Madrid, del 22 de abril al 2 de mayo de 1956) y la consulta realizada a las Academias correspondientes el 27 de marzo de 1957 por medio de la representación diplomática de España en los respectivos países, se introdujeron algunas modificaciones en ellas. El texto definitivo fue publicado por Julio Casares en el Boletín de la Real Academia Española (tomo XXXVIII, 1958) ${ }^{47}$ y declarado preceptivo a partir del 1 de enero de 1959. En las ediciones de 1959 y 1962 de la Gramática, la parte dedicada a la Ortografía no es modificada, y las Nuevas normas son incluidas en un apéndice al final.

En el Cuarto Congreso de Academias de la Lengua Española (celebrado en Buenos Aires, del 30 de noviembre al 10 de diciembre de 1964) se vio la conveniencia de publicar separado de la Gramática el texto de la Ortografía. Esta obra, en la que aparecen coordinadas la teoría tradicional sobre la acentuación y las innovaciones apuntadas, vio la luz en 1969 y tuvo una segunda edición en 1974. En el apartado del Esbozo dedicado a la Ortografía, incluida en la Fonología, como se desprende de su lectura y del

47 Casares, Julio, "Las nuevas normas de prosodia y ortografía”, Boletín de la Real Academia Española, XXXVIII, 1958, págs. 321-346 
artículo de Lidia Contreras $(1977)^{48}$, no se aprecian novedades básicas en relación con la Ortografía de 1969.

La Real Academia Española, con la colaboración con la Asociación de Academias de la Lengua Española, ante las dudas y sugerencias de numerosos hablantes, en 1999 publica otra edición de la Ortografía, "corrigiendo, actualizando y acrecentando la versión anterior con precisiones y ejemplos" ${ }^{\prime 49}$. Al intensificarse la atención a las variantes de uso de Hispanoamérica, una de las principales novedades es la adscripción "a efectos ortográficos" 50 de voces del tipo de fie (pretérito indefinido de fiar), hui (pretérito indefinido de huir), riais (presente de subjuntivo de reír), guion o Sion al grupo de los monosílabos, a pesar de lo cual se admite la utilización de la tilde "si quien escribe percibe nítidamente el hiato y, en consecuencia, considera bisílabas palabras como las mencionadas" ${ }^{\prime 1}$.

48 Contreras, Lidia, “La ortografía en el Esbozo de una nueva gramática de la lengua española", Estudios Filológicos, 12, 1977, págs. 59-80

49 Real Academia Española, Ortografía de la lengua española. Edición revisada por las Academias de la Lengua Española, Madrid, Espasa Calpe, 1999, pág. XIII.

50 Real Academia Española, Ortografía..., 1999, pág. 46.

51 Real Academia Española, Ortografía..., 1999, pág. 46. En el Diccionario panhispánico de dudas, la corporación corrobora la postura mantenida en la edición de 1999 de la Ortografía, matizando que "la pronunciación monosilábica es predominante en amplias zonas de Hispanoamérica, especialmente en México y en el área centroamericana, mientras que en otros países americanos como la Argentina, el Ecuador, Colombia y Venezuela, al igual que en España, es mayoritaria la pronunciación bisilábica" (Real Academia Española y Asociación de Academias de la Lengua Española, Diccionario panhispánico de dudas, Madrid, Santillana Ediciones Generales, 2005, s. v. tilde, §1.2). Por su parte, Manuel Seco, ante esta solución, opina que "la Academia está errada, y siembra con ello la confusión, cuando afirma que, 'a efectos ortográficos, son monosílabos las palabras en las que se considera [o sea, considera ella, la Academia] que no existe hiato - aunque la pronunciación así parezca indicarlo-, sino diptongo o triptongo' (Academia 1999, § 4.2). Se refiere a casos como fié (de fiar), hui (de huir), riáis (de reír), guión, Sión. Y en consecuencia afirma que debe suprimirse la tilde: fie, hui, guion, etc. Pero la pronunciación no 'parece indicar' que existe hiato: realiza hiato. Suprimir arbitrariamente la tilde que por tradición llevan estas palabras induce 
Habiéndose acordado en el XII Congreso de la Asociación de Academias de la Lengua Española (celebrado en San Juan de Puerto Rico, del 12 al 15 de noviembre de 2002) revisar la edición de 1999 de la Ortografía al observarse que en ella se habían sacrificado detalles importantes en aras de la sencillez y brevedad, se inició un proceso de examen del texto, junto con el de las reseñas y comentarios de autores particulares, que culminó en la ponencia presentada por el director de la Academia Chilena de la Lengua Alfredo Matus Olivier en el XIII Congreso de la Asociación de Academias de la Lengua Española (celebrado en Medellín [Colombia], del 22 al 24 de marzo de 2007) por encargo de la presidencia de la Asociación de Academias, en la cual se proponían las directrices de la nueva edición.

Las líneas esenciales del documento, aprobado en sesión plenaria del congreso, y ratificado en su desarrollo práctico por el pleno de directores y presidentes de las academias en una reunión celebrada en Madrid en noviembre de 2007, como se recoge

a una errónea lectura como monosílabos que deforma su estructura real bisilábica (fi-é, hu-í, gui-ón, etc.). Si fíe y fié se escriben sin tilde, es decir, fie, no hay forma de saber si la pronunciación es /fí-e/, /fi-é/ o /fie/. Lo mismo ocurrirá con río y rió si se escriben rio. Si en alguna zona fuera de España este tipo de palabras se pronuncia como monosílabo a pesar de la tilde, será un fenómeno natural de la forma local allí usada, análogo al que, en cualquier parte, se produce en la palabra ahí en sintagmas como ahí viene, /ái biéne/; fenómeno que, como otros muchos de la lengua oral, no tiene que alterar la forma escrita" (Seco, Manuel, Nuevo diccionario de dudas y dificultades de la lengua española, Barcelona, Espasa Libros, 2011, s. v. tilde, § 8). Antes, Julio Casares se había pronunciado al respecto en los siguientes términos: "Si en el encuentro io de guión, por ejemplo, hay tendencia general al hiato, no creemos que esta sea más perceptible que la que apreciamos en gorri-ón frente al diptongo franco o indiscutible de na-ción; y si en este caso y en tantos otros semejantes la escritura no tradujo la distinción, igualmente no podría hacerlo ahora so pena de sentar un precedente perturbador, a saber: En los encuentros de vocal débil seguida de fuerte acentuada, la tilde puesta sobre la fuerte equivale además a una diéresis sobre la débil, guión = guïon. Ahora bien, si para el hablante es indubitable, sin necesidad de diéresis, que guié, rué, huí, guió, etc., son vocablos bisílabos agudos, no hay para qué atribuir a la tilde valor dierético: estamos en plena regla general y por lo mismo que escribimos le-ón habremos de escribir gui-ón" (en Real Academia Española, Nuevas normas de prosodia y ortografía, Madrid, Imprenta de Silverio Aguirre Torre, 1952, pág. 86). 
en la Presentación de la obra, son las siguientes: “a) Las academias consideran necesaria una revisión de la Ortografía, pero se descarta la idea de una reforma ortográfica exhaustiva. // b) Es conveniente eliminar, dentro de lo razonable, la opcionalidad abierta por las llamadas normas potestativas. // c) Es necesario vigilar su coherencia con otras obras académicas" ${ }^{\prime 52}$.

La preparación de la nueva edición de la Ortografía le fue encomendada al Departamento de Español al día de la Real Academia Española, coordinado por la Comisión Interacadémica, que se reunió en Santiago y Valparaíso (Chile) (del 27 de febrero al 2 de marzo de 2010) y posteriormente en San Millán de la Cogolla (España) (del 1 al 4 de noviembre del mismo año) para discutir y solucionar las cuestiones más delicadas. Por fin, el texto fue aprobado por el pleno de los directores y presidentes de las academias en Guadalajara (México) (el 28 de noviembre de 2010) en el marco del homenaje rendido a la lengua española en la Feria Internacional del Libro. Como en el caso de la Nueva gramática (2009), de acuerdo con la tendencia tradicional de la institución, a la versión de referencia de la Ortografía (2010) le han seguido otras, la de la Ortografía básica (2012) y la de la Ortografía escolar (2013).

Teniendo en cuenta las directrices marcadas por la Real Academia Española y la Asociación de Academias de la Lengua Española en estas tres últimas obras, de acuerdo con las normas generales de la acentuación gráfica, llevan tilde en la sílaba tónica las palabras polisílabas agudas terminadas en vocal (maná, café, pirulí, plató, ambigú), en $n$ (balón, corazón, palafrén) o en s: anís, ciprés, compás ${ }^{53}$; las llanas que acaban en consonante distinta de $n$

52 Real Academia Española y Asociación de Academias de la Lengua Española, Ortografía..., 2010, págs. XXXVIII-XXXIX.

53 Por el contrario, se escriben sin tilde las palabras polisílabas agudas terminadas en consonante distinta de $n$ o $s$ (cantar, pared, relax), en más de una consonante (confort, minigolf, robots), o en $y$, ya que este grafema "se considera consonante a efectos de acentuación" (Real Academia Española y Asociación de Academias de la Lengua Española, Diccionario panhispánico, s. v. tilde, § 1.1.1): convoy, estoy, virrey. 
o s (lápiz, mármol, tóner), en más de una consonante (bíceps, cíborg, wéstern) - o en $y$, puesto que "se considera consonante a efectos de acentuación" 54 : póney, yérsey, yóquey ${ }^{55}-$; y todas las esdrújulas (análisis, hábitat, pétalo) y sobresdrújulas: revísaselo, tómasela, llévesemelas ${ }^{56}$.

Las palabras polisílabas que contienen diptongos en su estructura se acentúan gráficamente siguiendo las reglas generales, situándose, en su caso, la tilde, en los formados por vocal abierta precedida o seguida de vocal cerrada, sobre la vocal abierta (acción, camináis, Cáucaso), y en los construidos con dos vocales cerradas, sobre la segunda: acuífero, cuídate, lingüística. Cuando una palabra polisílaba con triptongo deba acentuarse de acuerdo con las reglas generales, la tilde se escribe sobre la vocal abierta: apreciáis, cambiéis, santiguáis. En las palabras polisílabas con hiatos, los constituidos por vocal cerrada precedida o seguida de vocal abierta llevan la tilde en la cerrada (serías, caído, transeúnte), y en los integrados por cualquier otro tipo de combinación se someten a las reglas generales: acordeón, teórico, rehén.

\footnotetext{
54 Real Academia Española y Asociación de Academias de la Lengua Española, Diccionario panhispánico, s. v. tilde, §1.1.2.

55 De esta manera, no llevan tilde las palabras polisílabas llanas terminadas en vocal (casa, noche, libro), en $n$ (cantan, joven, margen) o en s: chotis, crisis, tesis. Por lo que respecta a las voces de esta misma estructura acentual terminadas en $y$, la Real Academia Española, en el Diccionario (2014), en el caso de póney muestra su preferencia por poni, que figura como lema del artículo desarrollado, y en los de yérsey y yóquey, acepta también yersi y yoqui, que forman parte del lema junto a yérsey $\mathrm{y}$ yóquey como soluciones opcionales.
}

56 Las sobresdrújulas, como hace notar José Martínez de Sousa, "son voces en que el acento de intensidad carga en una sílaba situada antes de la antepenúltima. Se trata, en todos los casos, de tiempos verbales llanos o esdrújulos que se acrecientan con uno o más enclíticos (epéctasis)" (Martínez de Sousa, José, Diccionario de ortografía de la lengua española, Madrid, Paraninfo, 1995, s. v. acentuación, § 3.1.4). Con ello, tanto cuídamela como castíguesemele son palabras sobresdrújulas, radicando la diferencia entre ellas en que la tilde de cuídamela se encuentra situada en la sílaba anterior a la antepenúltima, y la de castíguesemele, dos sílabas antes. 
Al tratar la cuestión de los monosílabos, la Real Academia Española y la Asociación de Academias de la Lengua Española, dando un paso más con respecto a la solución adoptada en la Ortografía de 1999, acuerdan que, salvo los que deben llevar tilde diacrítica, no se acentúan, e incluyen entre los ejemplos de las palabras con diptongos o triptongos casos que en español normativo, de acuerdo con la interpretación de Julio Casares y Manuel Seco, entre otros, contienen, respectivamente, un hiato entre dos vocales (guion, fie, truhan), o un hiato entre una vocal y un diptongo (liais), subrayando que

el sistema de acentuación gráfica del español no tiene como función indicar si una secuencia vocálica se articula en una sola sílaba o en sílabas distintas (prueba de ello es que no distingue gráficamente va.ria.do de res.fri.a.do ni cui.da de hu.i.da, por ejemplo), de forma que la duplicidad gráfica en estos casos carece de justificación y constituye un elemento disgregador de la unidad de representación gráfica del español, cuyo mantenimiento es función esencial de la ortografía. Por ello, a partir de este momento, la convención que establece qué secuencias se consideran diptongos, triptongos o hiatos a efectos ortográficos debe aplicarse sin excepciones y, en consecuencia, las palabras antes mencionadas se escribirán obligatoriamente sin tilde, sin que resulten admisibles, como establecía la Ortografía de 1999, las grafías con tilde ${ }^{57}$.

Los monosílabos tónicos que deben llevar tilde diacrítica son los pronombres personales tú (Mañana vienes tú), él (Él ya lo sabe), mí: Es para mí; la forma sí, pronombre personal reflexivo (Ha vuelto en sî), adverbio de afirmación (Sí, lo haré) o sustantivo: El sí de las niñas; las palabras dé, del verbo dar (No le dé más caramelos), y sé, del verbo saber (No sé nada) o del verbo ser: Sé discreto; el sustantivo té: Póngame un té58; y la voz más, determinante (Ahora

57 Real Academia Española y Asociación de Academias de la Lengua Española, Ortografía..., 2010, pág. 236.

58 Ante la duda que le pudiera surgir a alguien al escribir, la Academia y la 
gana más dinero), pronombre (Ahora gana más), adverbio (Antes era más alegre), conjunción con valor de suma o adición (Tres más tres, seis) o sustantivo: Pon el más entre las cifras ${ }^{59}$.

Las palabras qué, quién, cuál, cuánto, dónde - y adónde-,cuándo, cómo son tónicas $\mathrm{y}$, por tanto, se escriben con tilde diacrítica cuando introducen estructuras claramente interrogativas y exclamativas, directas (¿Adónde vas?; ¿De quién ha sido la idea?; ¡Qué calor hace!) o indirectas (No sé a quién habrán elegido; Ya verás qué bien lo pasamos; No te imaginas cómo ha cambiado), pudiendo representarse gráficamente con tilde o sin ella en ciertos tipos de construcciones, especialmente las relativas de antecedente implícito indefinido de carácter inespecífico (Tiene en quién [o quien] confiar; No había dónde [o donde] esconderse; No encuentra dónde [o donde] alojarse) y las que pueden interpretarse como interrogativas indirectas o como relativas: Responde una cosa u otra según quién (o quien) pregunte; No me gusta cómo (o como) me mira; Depende de cuándo (o cuando) sea ${ }^{60}$.

Asociación de Academias de la Lengua Española incluyen en el texto la advertencia de que el plural tés mantiene la tilde diacrítica del singular (Real Academia Española y Asociación de Academias de la Lengua Española, Ortografía..., 2010, pág. 243; Ortografía básica de la lengua española, Madrid, Espasa Libros, 2012, pág. 46; Ortografía escolar de la lengua española, Madrid, Espasa Libros, 2013, pág. 32).

59 Frente a los monosílabos tónicos con tilde diacrítica apuntados, se escriben sin tilde los átonos correspondientes $t u$, determinante posesivo: He estado en tu pueblo; el, artículo: El tren llegará con retraso; mi, determinante posesivo (Vamos en mi coche) o sustantivo: Empieza en mi natural; si, conjunción (Si queréis, lo terminamos mañana) o sustantivo: La obra está en si bemol; te, pronombre personal: No te había visto; de, preposición: Procede de Extremadura; se, pronombre personal reflexivo: María se preparó la cena; y mas, conjunción adversativa: La cogida fue grave, mas no tanto como parecía. La conjunción $o$, en su calidad de palabra monosílaba átona, como se ha podido comprobar, también ha quedado excluida de la lista de las palabras portadoras de tilde diacrítica, aunque se encuentre situada entre cifras (El artículo tendrá una extensión de 11 o 12 páginas) o signos matemáticos: Escriba los signos +o - en las casillas correspondientes.

60 Real Academia Española y Asociación de Academias de la Lengua Española, Ortografía..., 2010, págs. 245-268; Ortografía básica..., págs. 47-54; Ortografía escolar..., págs. 32-33. Estas palabras, cuando funcionan como relativos, con antecedente 
El vocablo solo, tanto cuando es adjetivo (Está solo todo el día) como cuando es adverbio (Solo come verdura y pescado), no debe llevar tilde según las normas generales de la acentuación. Respecto a los demostrativos este, ese, aquel, y paradigmas, funcionen como determinantes (esta mesa, ese ordenador, aquel bolígrafo) o como pronombres (Esta es muy lista; Ese sabe bien lo que hace; Aquellas trabajaban en El Corte Inglés), la Academia y la Asociación de Academias de la Lengua Española acuerdan que "a partir de ahora se podrá prescindir de la tilde en estas formas incluso en casos de doble interpretación" ${ }^{\prime \prime 1}$, que la mayor parte de las veces son resueltos por el contexto comunicativo ${ }^{62}$.

La acentuación gráfica de las formas o expresiones complejas depende de si se escriben en una sola palabra o en varias. Las voces compuestas por aglutinación, en las que solo se acusa el acento prosódico de su último componente, siguen las reglas generales de la acentuación: baloncesto, ciempiés, tiovivo. En las expresiones complejas constituidas por varias palabras unidas con guion, cada una de ellas mantiene su acentuación: épico-lírico, físico-químico, Madrid-París-Berlín. Los adverbios terminados en -mente mantienen la tilde del adjetivo si este la lleva: amablemente, dócilmente, rápidamente. Las formas verbales con pronombre enclítico se acentúan siguiendo las reglas generales: cállate, dime, bé-

expreso o sin él, al ser átonas excepto cual (precedida de artículo), se escriben sin tilde: Ha colocado en el jarrón las flores que le trajeron; Quien siembra vientos recoge tempestades; Ese es el motivo por el cual no aceptó el cargo; Anotaba cuantas novedades observaba; Buscaba un lugar donde guarecerse; Llegó cuando estaba amaneciendo; Escribe como habla.

61 Real Academia Española y Asociación de Academias de la Lengua Española, Ortografía..., 2010, pág. 169.

62 En cuanto a aún y aun, hemos de matizar que aún es considerada una palabra bisílaba tónica con hiato que se escribe con tilde cuando tiene valor temporal ( $E l$ paquete no me ha llegado aún) o ponderativo: Laura es más diligente aún que Olga; sin embargo, aun es interpretada como un monosílabo átono con diptongo que no lleva tilde en aquellos otros casos en los que equivale a hasta, también, incluso (o, precedido de ni, siquiera) (Ni aun de cerca distingue los colores) o tiene valor concesivo: Continuó insistiendo aun cuando nadie le apoyaba. 
betelo. En las expresiones complejas formadas por varias palabras independientes, tanto si mantienen su acento prosódico como si lo pierden, conservan la acentuación gráfica que les corresponde como elementos autónomos: sofá cama, tío abuelo, José María.

Las voces o expresiones de otras lenguas, incluido el latín, no adaptadas al español - extranjerismos crudos - se escriben con la grafía propia de la lengua original y en cursiva (o entre comillas, en los textos manuscritos) (ad libitum, apartheid, pizza), mientras que las adaptadas a la pronunciación y escritura de nuestra lengua llevan tilde cuando lo exigen las reglas generales de la acentuación: champú, cuórum, mitin. Los latinismos crudos concretamente "se escriben en su grafía originaria y sin añadir signos ajenos al sistema latino de escritura, esto es, sin tildes, ya que el latín carece de ellas" ${ }^{\prime \prime}$, debiéndose marcar gráficamente su carácter foráneo por los mismos procedimientos que cuando se usan palabras o expresiones de cualquier otro idioma ${ }^{64}$.

\section{Conclusiones}

En la investigación llevada a cabo tradicionalmente sobre la naturaleza del acento en español, mientras que en unos casos se recalca que está en función del tono o de la cantidad y el tono, en otros se defiende que es consecuencia de la intensidad, llegándose incluso a veces a conjugar ambas tendencias en la misma caracterización. Sin embargo, al examinar los trabajos de mayor

63 Real Academia Española y Asociación de Academias de la Lengua Española, Ortografía..., 2010, pág. 607.

64 La tilde de las palabras plenas se mantiene en las abreviaturas si estas incluyen la vocal que la llevaba en aquellas: admón. (administración), pág. (página), pról. (prólogo). Las siglas escritas en mayúsculas se representan siempre sin tilde: CIA, FMI, OTAN. Sin embargo, los acrónimos que se han convertido en nombres comunes o propios se encuentran sometidos a las reglas generales de la acentuación: láser, ovni, Fundéu. Los símbolos internacionales se escriben sin tilde aunque la palabra correspondiente en español la tenga: a (área), lim (límite), Ex (Éxodo). 
impacto realizados con los métodos de la fonética acústica, se comprueba que el tono es el elemento principal, y la duración y la intensidad, factores de segundo orden.

En español, lengua de acento libre como el inglés o el italiano, el prosodema acentual, caracterizado como el mayor grado de prominencia con el que se pronuncia una sílaba en relación con las otras de la misma palabra o el grupo acentual del que forma parte, desempeña las funciones contrastiva, distintiva, culminativa y focalizadora, resultando las palabras acentuadas o tónicas, sobre todo las bisílabas llanas, más abundantes que las inacentuadas o átonas. En el dominio superior a la palabra se observa que las sílabas acentuadas o tónicas actúan como los puntos de anclaje de las inflexiones melódicas del tono fundamental.

La ortografía del español, tras los avatares experimentados desde mediados del siglo XVI, en que comienzan a emplearse signos diacríticos para indicar la sílaba tónica en determinadas palabras, seleccionados los aspectos más certeros de las normas propuestas por destacados especialistas de todas las épocas, tal como se encuentra fijada en la actualidad, señala el acento de forma regular y prácticamente exhaustiva. A ello ha contribuido de manera especial la labor de la Real Academia Española a partir del siglo XVIII, cuya actividad cobra un nuevo impulso a mediados del siglo XX y culmina en nuestros días con las recientes publicaciones, en las que con la colaboración de la Asociación de Academias de la Lengua Española se intensifica la atención a las variantes de uso de Hispanoamérica.

Luis Alberto Hernando Cuadrado Universidad Complutense de Madrid 